\title{
Técnicas de cirugía mucogingival para el cubrimiento radicular
}

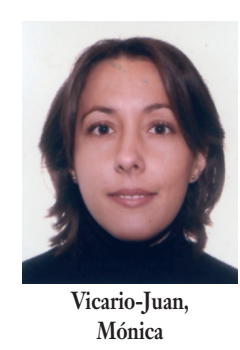

\author{
Mucogingival surgical procedures to attain root coverage
}

\section{Vicario-Juan, Mónica * Pascual-La Rocca, Andrés Vives-Bonet, Ma Teresd ${ }^{* *}$ Santos-Alemanny, Antonio}

*Certificado de Periodoncia e Implantes. Tufts University. Boston, USA. Profesora asociada del Máster de Periodoncia de la Universitat Internacional de Catalunya, Barcelona

**Profesor asociado del Máster de Periodoncia de la Universitat Internacional de Catalunya, Barcelona.

***Alumna del Máster de Periodoncia de la Universitat Internacional de Catalunya, Barcelona.

$* * * *$ Director del Máster de Periodoncia de la Univesitat Internacional de Catalunya, Barcelona.
Resumen: La recesión radicular puede desencadenar problemas de hipersensibilidad, caries radicular y problemas estéticos. Para corregir estos defectos y cubrir las superficies denudadas de las raíces se han propuesto gran variedad de técnicas de cirugía plástica periodontal. El propósito de este artículo es realizar una descripción detallada de diferentes procedimientos quirúrgicos para el cubrimiento radicular. Las técnicas de injerto gingival libre, injertos conectivos subepiteliales e injertos de matriz dérmica acelular son descritas paso a paso, según se encuentran definidas en la literatura.

Para conseguir la máxima predictibilidad en el cubrimiento de las raíces denudadas es imprescindible diagnosticar con exactitud el caso y observar detalladamente todos los pasos de la técnica quirúrgica.

Palabras clave: Cubrimiento radicular, Tratamiento recesiones radiculares, Cirugía mucogingival.

Abstract: Gingival recessions may be associated with problems such as dental hypersensitivity, root caries and unacceptable aesthetics. Different techniques are proposed in order to achieve root coverage and correction of the mucogingival defects.

The purpose of this article is to present a review and the description of the most common procedures for root coverage. Among these techniques, the most popular procedures are the free gingival graft, the connective tissue grafts and acellular dermal grafts.

In order to select the most predictable technique for root coverage, a proper diagnosis has to be established.

Key words: Root coverage, Gingival recessions treatment, Mucogingival surgery.

\section{Correspondencia}

Mónica Vicario

Universitat Internacional de Catalunya

Area de Periodoncia

Josep Trueta s/n

Sant Cugat del Vallés.

08190 Barcelona

E-mail: mvicario@hotmail.com
Vicario-Juan M, Pascual-La Rocca A, Vives-Bonet MT, Santos-Alemany A. Técnicas de cirugía mucogingival para el cubrimiento radicular. RCOE 2006;11(1):61-73.
BIBLID [1138-123X (2006)11:1; enero-febrero 1-140] 


\section{Introducción}

Cada día es más frecuente observar la preocupación de los pacientes por la presencia de recesiones gingivales localizadas 0 generalizadas. El paciente puede referir sensibilidad, 0 presentar una mayor prevalencia de caries y abrasiones cervicales, pero suele ser el compromiso estético el principal motivo de consulta.

Guinard y Caffesse en 1978', definieron la recesión gingival como el desplazamiento del tejido gingival marginal hacia la zona apical del límite amelocementario, dando lugar a la exposición de la superficie radicular. La recesión del tejido marginal puede estar asociada a diversas causas, entre las que podemos incluir: traumatismo tras cepillado vigoroso, malposición dentaria, restauraciones, inadecuada higiene oral, movimientos ortodóncicos, tracción de frenillos y enfermedad periodontal, principalmente.

Ante la presencia de recesiones podemos plantear dos posibilidades: en primer lugar, no tratarla y controlar su evolución; en segundo, corregirlas mediante la práctica de técnicas de cirugía mucogingival. Entre estas técnicas se encuentran injertos preventivos de tejido blando que buscan aumentar el ancho de la encía queratinizada o técnicas de cubrimiento radicular. Esta última opción será el objetivo de esta revisión.

\section{Diagnóstico de las recesiones radiculares}

Previo a la selección del tratamiento, el profesional deberá evaluar y cla-

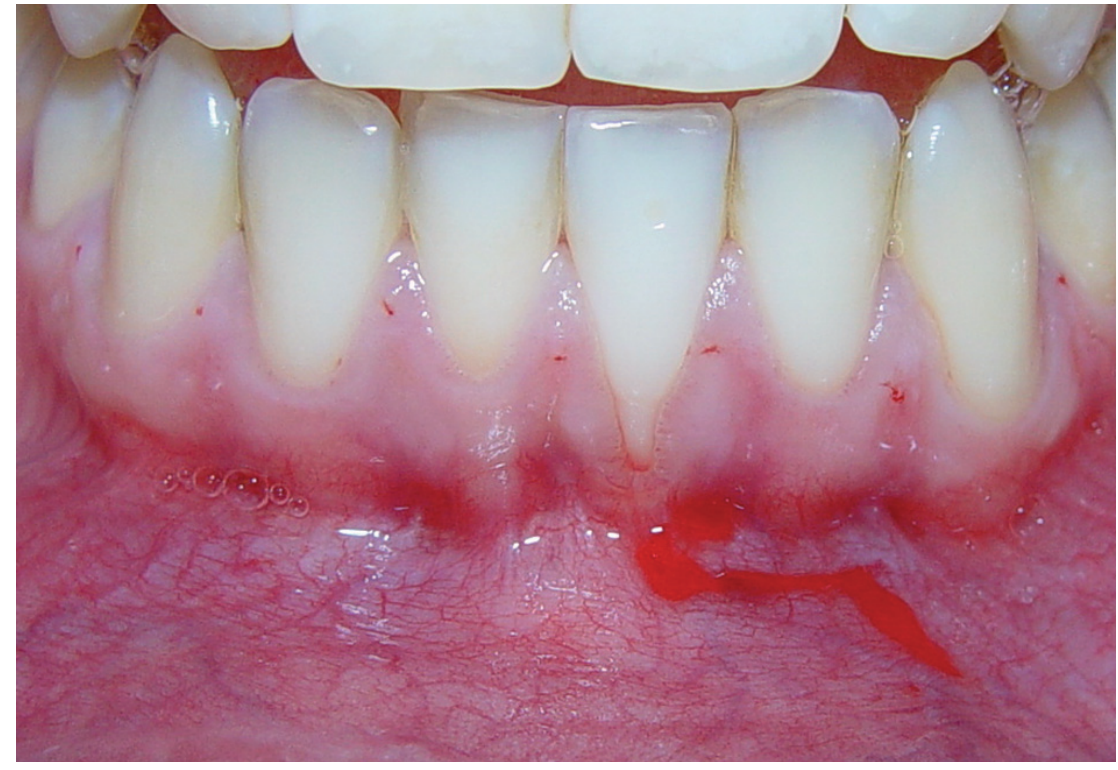

Figura 1. Recesión Clase I Miller.

sificar el tipo de recesión. Según la predictibilidad en el cubrimiento radicular Miller presentó la siguiente clasificación en $1985^{2 * *}$ :

- Clase I: la recesión de tejido marginal no se extiende más allá de la línea mucogingival. No hay pérdida de hueso ni tejido blando interdentario. Se puede conseguir el cubrimiento completo de la recesión de manera predecible (fig. 1).

- Clase II: recesión del tejido marginal que se extiende hasta la línea mucogingival o la sobrepasa. No hay pérdida de hueso ni tejido blando interdentario. Se puede conseguir el cubrimiento completo de la recesión de manera predecible (fig. 2).

- Clase III: recesión del tejido marginal que se extiende hasta la línea mucogingival o más allá. La pérdida de hueso o tejido blando interdentario es apical al límite amelocementario pero coronal a la extensión apical de la recesión de tejido marginal o existe malposición dentaria. Sólo podremos alcanzar un cubrimiento parcial de la recesión (fig. 3).

- Clase IV: recesión de tejido marginal que se extiende más allá de la unión mucogingival. La pérdida de hueso interdentario se extiende a un nivel apical a la extensión de la recesión del tejido marginal. Puede existir malposición dentaria. No se puede esperar un cubrimiento de la superficie radicular de manera predecible (fig. 4).

Esta clasificación sólo representa una guía para determinar el pronóstico del tratamiento pero hay otros factores a considerar, como la profundidad del vestíbulo, la convexidad radicular, la presencia de abrasiones radiculares, la dimensión de las papilas, el desequilibrio acentuado entre el plano óseo y dental, la proporción entre el área avascular/vascular, entre otros.

De todo ello se desprende que la predictibilidad de un recubrimiento radicular completo es mayor en aque- 


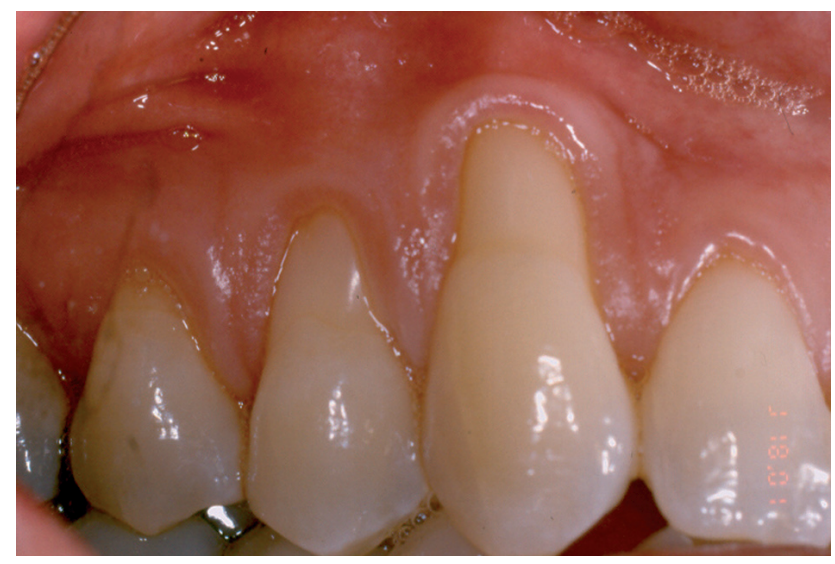

Figura 2. Recesión Clase II Miller.

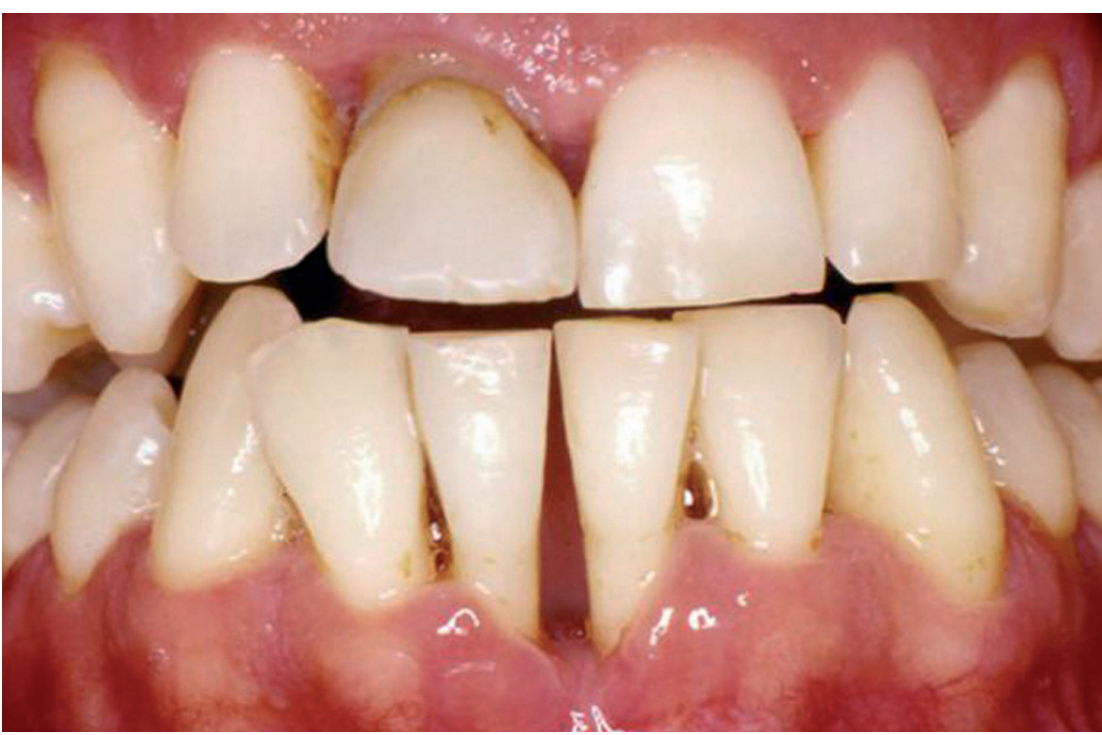

Figura 4. Recesión Clase IV Miller.

llas recesiones que no presenten pérdida de soporte interproximal. Otros factores de riesgo que contraindicarían la realización de técnicas de cubrimiento radicular son la existencia de malposición dentaria severa, que requiere tratamiento ortodóncico previo, hábitos de higiene oral inapropiados que deben ser corregidos antes de la intervención y el hábito tabáquico. En efecto, el tabaco interfiere en la cicatrización y contribuye a la destrucción periodontal; así deberíamos recomendar a nuestros pacientes abandonar tal hábito ${ }^{3 *}, 4$

Según los criterios utilizados por Miller en sus publicaciones, se acepta que el recubrimiento radicular es completo cuando, tras el período de cicatrización, el margen gingival se localiza a nivel de la línea amelocementaria, existe inserción clínica en la raíz, la profundidad del surco es de $2 \mathrm{~mm}$ o menor y no existe sangrado al sondaje ${ }^{5}$.

\section{Tratamiento para el cubrimiento radicular}

Para corregir los defectos mucogingivales y cubrir las superficies denudadas de las raíces se han propuesto varias técnicas de cirugía plástica periodontal:

A. Autoinjertos pediculados: colgajos rotacionales o desplazados coronalmente, no serán el objetivo de nuestra revisión.

B. Autoinjertos de tejidos blandos libres: gingival libre y tejido conectivo subepitelial.

C. Técnicas quirúrgicas basadas en regeneración tisular guiada (RTC), con membranas reabsorbibles o no reabsorbibles.

D. Injerto dérmico acelular, Alloderm ${ }^{\circledR}$

\section{Injerto gingival libre}

Esta técnica quirúrgica fue descrita por Sullivan y Atkins en $1968^{6^{*}}$ con el objetivo de aumentar el grosor de encía queratinizada y posteriormente modificada por Miller en $1982^{5}$ para el cubri- 


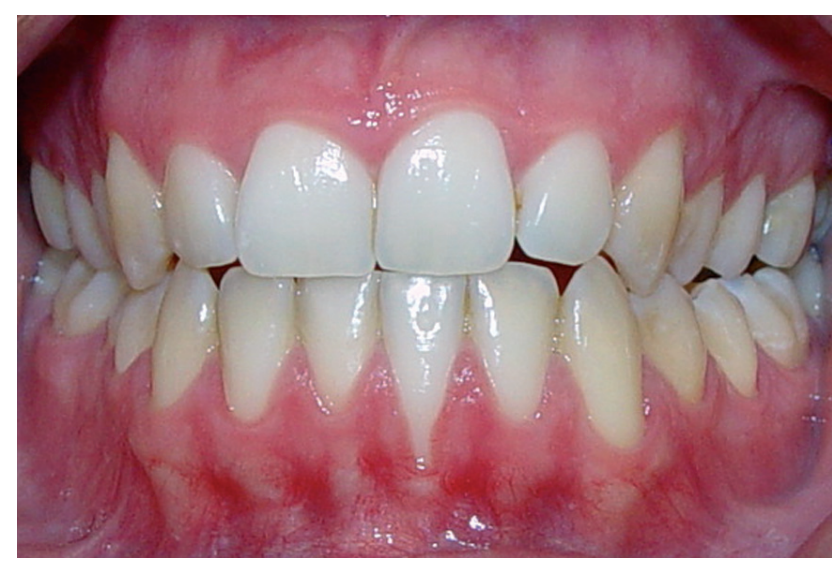

Figura 5. Recesión Clase II Miller \#31.

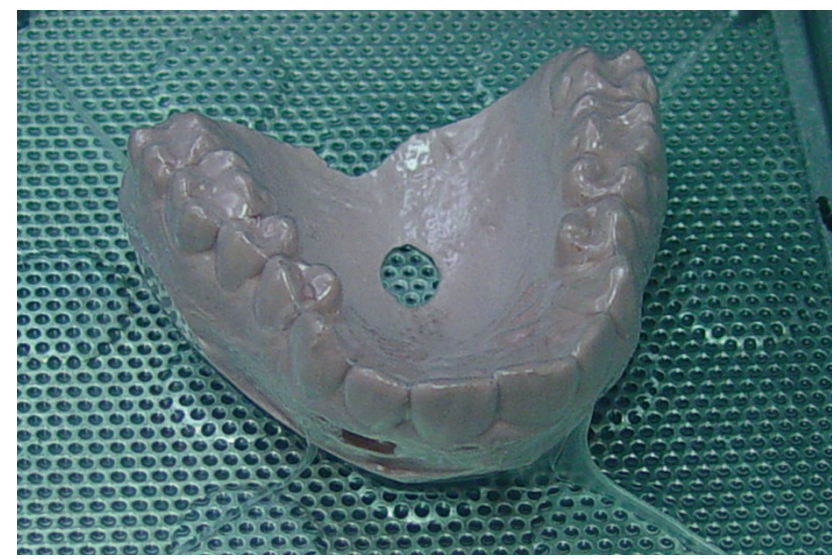

Figura 7. Confección de la férula acrílica.

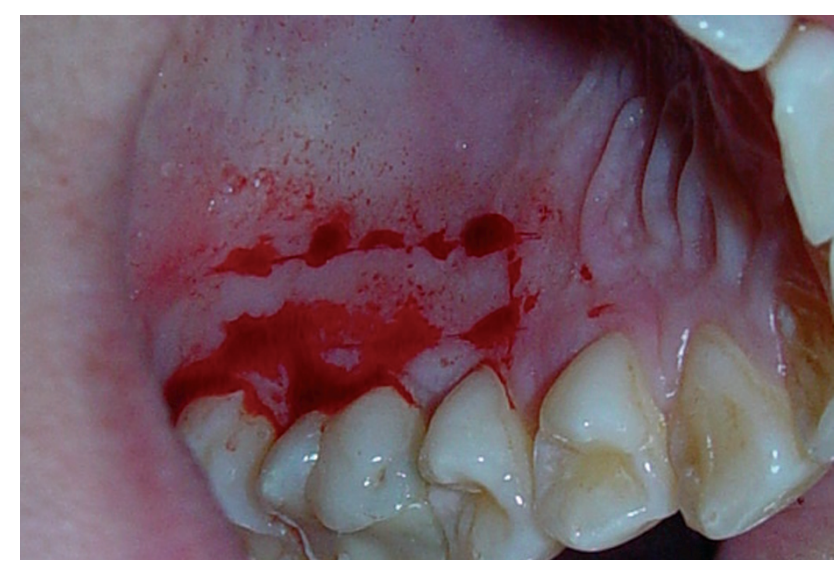

Figura 6. Incisiones en paladar.

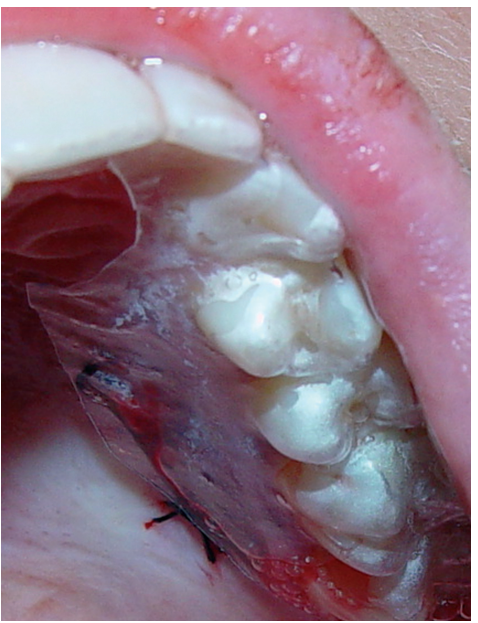

Figura 8

Adaptación

de la férula

en el paladar. miento de recesiones radiculares (fig.5).

Los pasos quirúrgicos para el cubrimiento radicular con injerto gingival libre son los siguientes:

A. Preparación del lecho receptor: se prepara un colgajo de espesor parcial que se extiende en sentido apical unos $5 \mathrm{~mm}$ más allá de la dehiscencia ósea y en sentido mesiodistal alcanza un diente más a cada lado de la zona a tratar. La incisión será horizontal con el bisturí orientado perpendicularmente a la base de las papilas, a nivel de la línea amelocementaria o coronal a ésta. Se extiende hasta casi el ángulo diedro de los dientes adyacentes a
Ios dientes a tratar. Con esta incisión coronal se busca una buena adaptación entre el injerto y la base de las papilas y una correcta vascularización del tejido donante. De las incisiones horizontales parten dos incisiones verticales paralelas entre sí, que se prolongan hasta la porción apical del lecho receptor ya preparado. Mediante el bisturí o tijeras, se diseca la encía hasta obtener un lecho perióstico firme e inmóvil9.

B. Preparación de la superficie radicular. Haciendo uso de curetas y/o fresas se acondicionan las superficies radiculares a cubrir eliminando el cál- culo y cemento necrótico. Si la curvatura de las raíces es exagerada se puede intentar reducir la convexidad, consiguiendo al mismo tiempo la reducción de la dimensión mesiodistal de la raíz y la disminución entre el plano óseo y el plano radicular, evitando la creación de espacios muertos al adaptar el tejido donante al lecho receptor. La proporción entre el área avascular y el área vascular debe ser favorable a la segunda. Ésta es la base para el procedimiento del injerto? aunque el acondicionamiento radicular también puede hacerse por métodos químicos como el ácido cítrico ${ }^{5,10}$ 

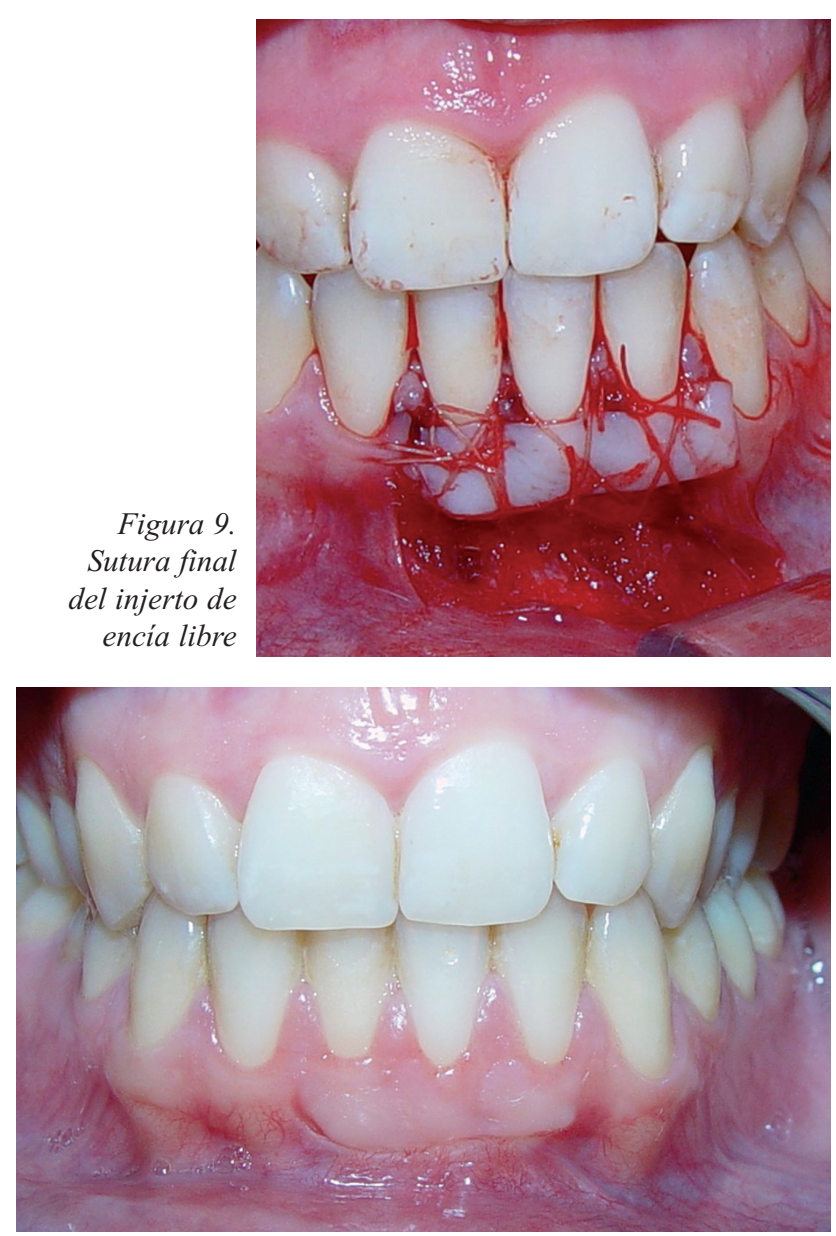

Figura 11. Resultado final al mes.

o el clorhidrato de tetraciclina. En sus estudios, Miller preconizó el uso del ácido cítrico con el fin de eliminar la capa de barrillo dentinario, facilitar la formación de una nueva inserción de tejido fibroso por la exposición de las fibras de colágeno de la dentina y permitir la unión de estas fibras con las del tejido conectivo del injerto. Sin embargo, en estudios controlados donde se comparaba la misma técnica con y sin aplicación del ácido no se observaron diferencias clínicamente significativas ${ }^{10,11^{*}}$.

C. Obtención del tejido donante: previamente debemos analizar algunas

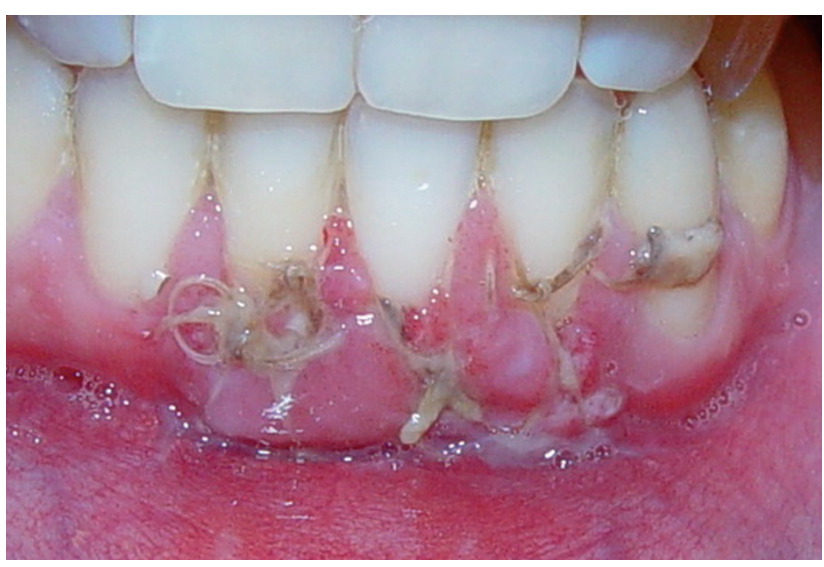

Figura 10. Postoperatorio a los 8 días.

consideraciones anatómicas co-mo el grosor de la fibromucosa palatina o la altura de la bóveda palatina. En bóvedas planas el riesgo de seccionar la arteria palatina es mayor, se aconseja, por tanto, evitar zonas adyacentes al segundo molar.

Según Sullivan y Atkins, el aspecto mas importante es la obtención del tejido donante de manera atraumática, evitando lesionar los vasos que pueden comprometer la vascularización ${ }^{6^{*}}$. Las incisiones serán en ángulo recto y no biseladas, consiguiendo un grosor uniforme. Estudios de Soenren, Allen, Cutright y Seibert señalan que un injerto de 1,5 $\mathrm{mm}$ de grosor parece ser el que mayor índice de supervivencia obtiene ante una raíz denudada ${ }^{11^{*}}$ (fig. 6).

Para minimizar las molestias durante la cicatrización de la zona donante del paladar se realiza una férula acríli- ca que protegerá la herida quirúrgica, proporcionando así un mayor confort al paciente (figs. 7 y 8).

D. Sutura: se precisa la fijación del tejido donante al lecho receptor. Se recomienda el uso de suturas de 4-0 o 5-0 reabsorbibles o no. El borde coronal del injerto se une con la base de las papilas mediante puntos de sutura simples. Se realizan puntos de sutura en cruz que compriman el tejido donante contra las raíces del lecho receptor (fig. 9).

Entre las diferentes técnicas de sutura existentes destacamos las suturas suspensorias, que no perforan el tejido donante, se anclan en el periostio y alrededor de los dientes y comprimen el injerto contra el lecho receptor. La inmovilización del injerto es importante para su supervivencia. Se aconseja realizar presión durante cinco minutos sobre el injerto para desplazar la sangre por debajo de éste y conseguir aproximar el lecho al injerto 5 (figs. 9 a 11).

El cubrimiento radicular también puede realizarse en dos fases quirúrgicas. En 1975, Bernimoulin la describió de la siguiente manera: primero 


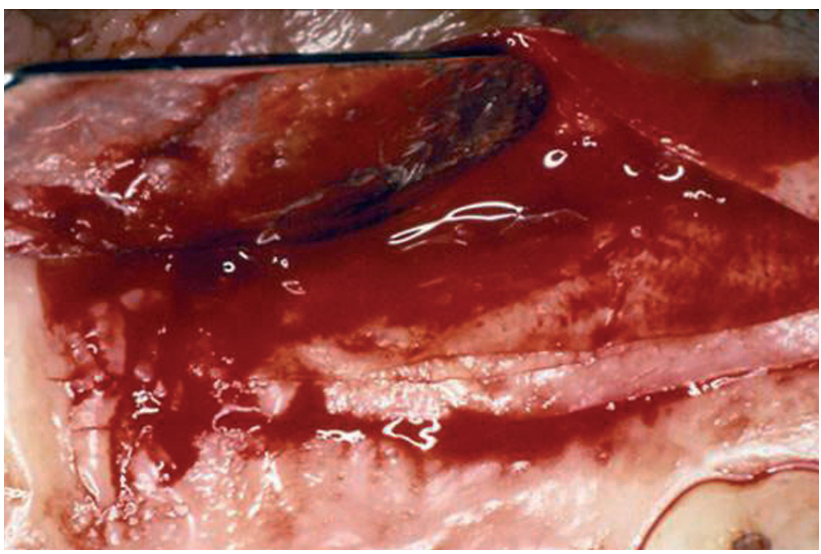

Figura 12. Técnica de ventana con cuatro incisiones. afectada y se cubre por un colgajo reposicionado coronalmente.

con el objetivo de disminuir al máximo el riesgo en la vascularización del injerto, esta técnica ha sufrido modificaciones en el diseño del lecho; en 1985, Raetzke ${ }^{13}$ hizo posible la

se realiza un injerto gingival libre apical a la zona con recesión para aumentar la encía queratinizada y pasadas seis semanas, se recoloca coronalmente el injerto para conseguir el cubrimiento radicular ${ }^{8}$. Esta técnica ha ido perdiendo aceptación debido a las ventajas que ofrece la técnica de Miller, que en un solo paso consigue el cubrimiento radicular de forma predecible (en el $89,9 \%$ de los casos, con un cubrimiento radicular completo) ${ }^{5}$.

\section{Injerto de rejido conectivo subepitelial}

En 1985, Langer y Langer fueron los primeros autores en describir el uso del injerto de tejido conectivo subepitelial. Este procedimiento permite aumentar la cantidad de encía queratinizada, así como conseguir cubrimiento radicular ${ }^{12^{* *}}$.

El tejido conectivo donante es obtenido del interior de la fibromucosa palatina. Posteriormente es colocado sobre un lecho receptor en la zona inserción del tejido a través de un sobre, mientras que Allen ${ }^{14^{4}}$ Io consiguió mediante la técnica del túnel.

En la literatura se describen diferentes variantes de la técnica según el tipo de colgajo que cubrirá el tejido conectivo en el lecho receptor y también según la técnica de obtención del injerto de la zona palatina donante.

\section{Técnicas para la obten- ciōn del rejido conectivo}

Tras la anestesia y haciendo uso de la sonda periodontal valoramos el grosor del paladar. Se recomienda un grosor mínimo del paladar de $4 \mathrm{~mm}$. El espesor mínimo para el tejido donante está entre $1,5 \mathrm{~mm}^{9}$ y $2 \mathrm{~mm}^{5}$.

1. Técnica con incisiones liberadoras: consiste en dos incisiones verticales y una incisión horizontal que las une. Se recomienda que la extensión horizontal sea mayor que la vertical para evitar comprometer la vascularización del paladar. Se trata de una técnica sencilla que permite una buena visibilidad y un acceso fácil , pero con mayor riesgo de necrosis del colgajo palatino ${ }^{13}$.

2. Técnica de ventana con cuatro incisiones: comprende dos incisiones horizontales y paralelas al plano oclusal y separadas de 1,5 a $2 \mathrm{~mm}$, y dos incisiones verticales formando un ángulo de $90^{\circ}$ respecto a las anteriores. Desde la incisión horizontal más alejada del margen gingival disecaremos el tejido conectivo con bisturí manteniendo una inclinación de aproximadamente $135^{\circ}$ respecto al eje del diente. Partiendo de la incisión más cercana al margen gingival, con un periosototomo se desinserta el tejido donante. Posteriormente suturamos la ventana, dejando una pequeña superficie que cicatrizará por segunda intención y que no supone morbilidad postoperatoria. Obtendremos de esta manera un injerto con un ribete de epitelio (fig. 12).

3. Técnica de ventana con tres incisiones: se realiza una incisión horizontal paralela al plano oclusal y dos pequeñas incisiones liberadoras perpendiculares a la anterior. Desde la horizontal se abre una ventana para tener acceso al interior de la fibromucosa palatina; con un bisturí se secciona todo el contorno del injerto que se desea obtener y con un periostotomo se despega el tejido donante. Al suturar se consigue un cierre primario de la herida palatina. El tejido donante sólo corresponde a tejido conectivo.

4. Técnica de la L invertida: se realiza una primera incisión horizontal perpendicular al hueso. Desde su extremo anterior realizaremos una pequeña incisión vertical perpendicular a la anterior. Posteriormente, separamos el colgajo para acceder con el bisturí al interior y delimitar el tamaño del injerto. Con un periostotomo se diseca el tejido donan- 

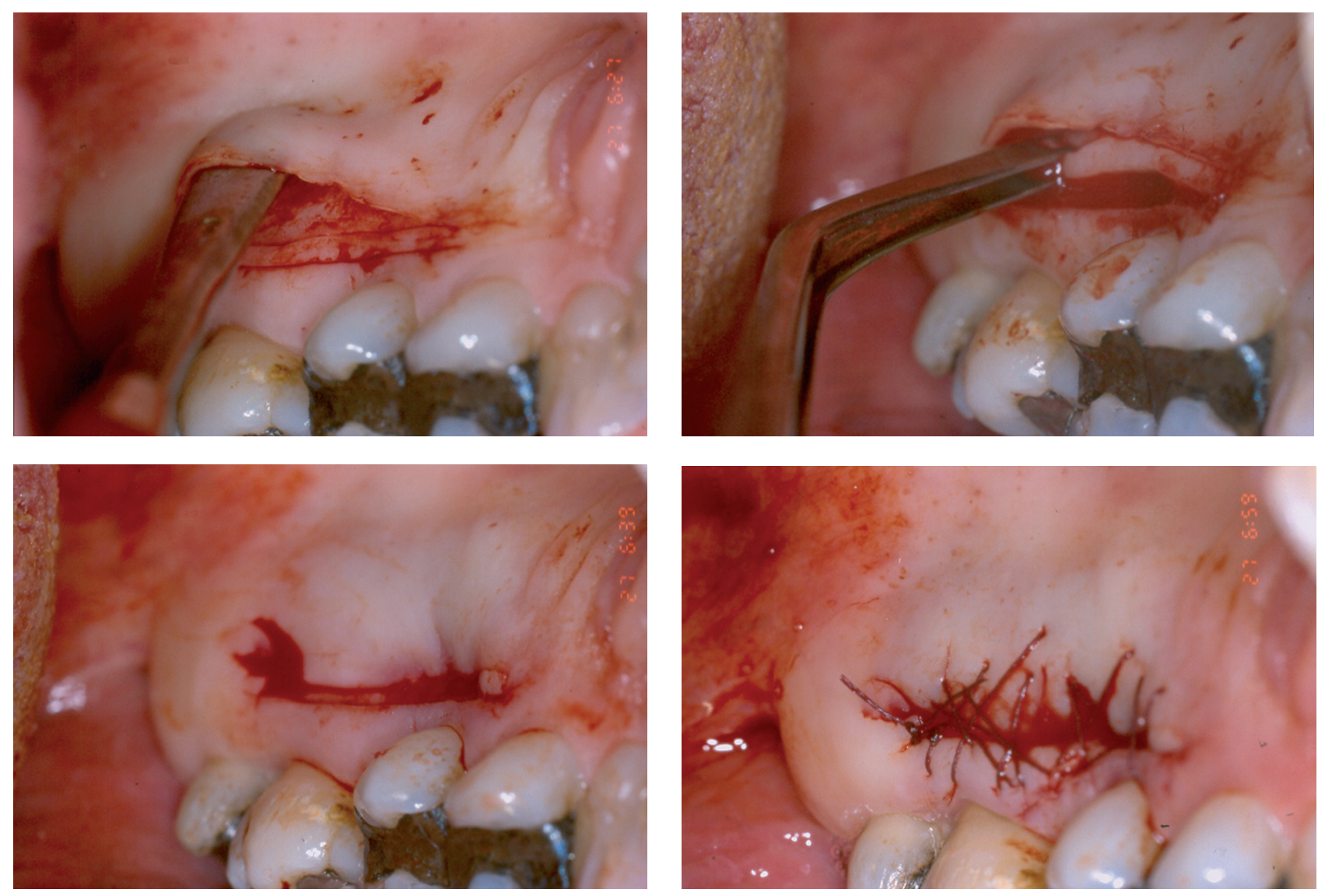

Figura 13. Pasos para la obtención del injerto con técnica de dos incisiones horizontales.

te obteniendo así el tejido conectivo sin ribete de epitelio.

5. Técnica con dos incisiones horizontales: la primera incisión será horizontal, aproximadamente a 2 o $3 \mathrm{~mm}$ desde el margen gingival hasta hueso; la segunda incisión la realizaremos de 1,5 a $2 \mathrm{~mm}$ respecto a la primera y paralela a ella. A partir de esta incisión se realiza la disección hasta alcanzar el perímetro deseado. Desde la primera incisión se despega el tejido donante. Esta técnica permite la obtención de un tejido conectivo con ribete epitelial, dejando una pequeña zona del paladar que cicatrizará por segunda intención.

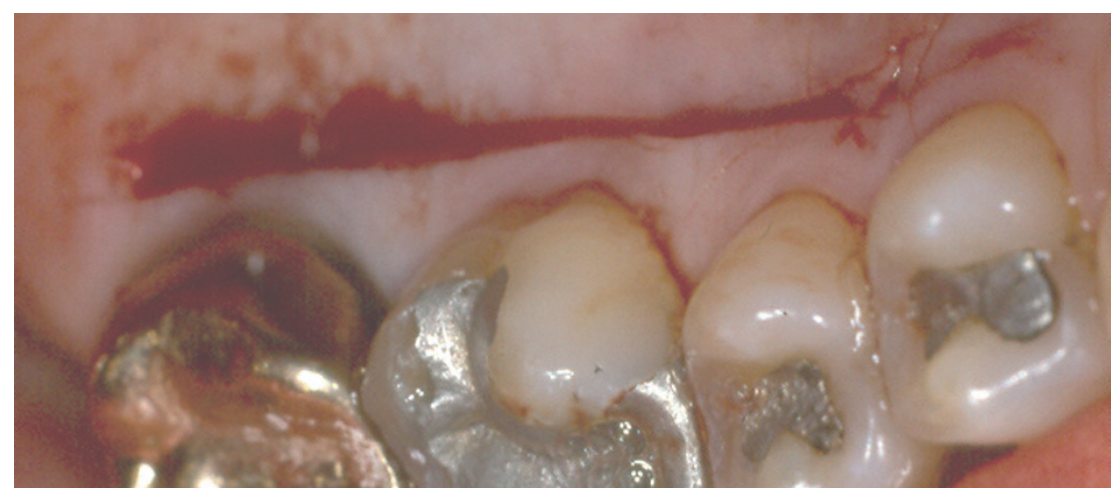

Figura 14. Técnica con una incisión horizontal.

La comparación entre esta técnica y la técnica con incisiones liberadoras no evidencia diferencias en cuanto al cubrimiento radicular, pero sí una menor morbilidad postoperatoria ${ }^{15}$ (fig. 13)

6. Técnica con una incisión horizontal: realizaremos una incisión horizontal 
larga hasta el hueso; con una inclinación de aproximadamente $135^{\circ}$ del bisturí respecto al eje del diente. Se realiza una disección de 1,5 $\mathrm{mm}$ hacia la línea media. Posteriormente se traza con un bisturí todo el perímetro del injerto que se despegará con un periostotomo. Conseguiremos un tejido sin ribete epitelial y por tanto el cierre primario del paladar (fig. 14)

\section{Técricas según}

el lipo de colgajo que cubre el injerto de teijdo coneclivo [ITC]

\section{ITC con colgajo parcial reposicionado en sentido coronal}

Descrita por Langer y Langer en 1985, se realiza para el tratamiento de recesiones localizadas y generalizadas. con ella se busca aumentar la predictibilidad en el cubrimiento radicular de zonas amplias y profundas del maxilar. Se hace una primera incisión horizontal a nivel de la línea amelocementaria en el espacio interpapilar, y con una incisión intrasulcular conectamos las anteriores. Las verticales liberadoras parten de las horizontales y van biseladas hacia el centro del colgajo sobrepasando la línea mucogingival. De esta manera levantaremos un colgajo de espesor parcial.

Se acondiciona mecánicamente las raíces a cubrir con raspado y alisado y sin la aplicación de acondicionadores radiculares. El tejido conectivo se obtiene con un ribete de epitelio, el cual se coloca en la zona marginal de la recesión.

Se fija el injerto al lecho receptor con puntos de sutura preferiblemente reabsorbible de 5-0 o 6-0. Para obtener el cubrimiento del tejido donante desplazaremos el colgajo en sentido coronal y lo fijamos con puntos de sutura suspensoria en la parte coronal y con puntos simples en las descargas.

El injerto está provisto de una doble vascularización que proviene del tejido conectivo del lecho y del tejido conectivo del colgajo. Además de una mayor vascularización del injerto con esta técnica buscamos un mejor resultado estético, y al realizar un abordaje palatino menos traumático conseguimos minimizar las molestias postoperatorias ${ }^{12^{* *}}$

La técnica original de Langer y Langer no preconiza el cubrimiento total del tejido conectivo con el colgajo; en cambio, en 1986 Nelson describió la técnica cubriendo totalmente el tejido conectivo para asegurar la viabilidad del injerto ${ }^{12^{* *}, 16}$ (fig.15).

\section{ITC en sobre supraperiós- tico}

Descrita por Raetzke en 1985, para el tratamiento de recesiones aisladas con el fin de mejorar la nutrición y el soporte del injerto. Tras la preparación mecánica de la superficie radicular, reflejamos un colgajo de espesor parcial partiendo desde el margen de la recesión, y creamos un lecho receptor tres veces más ancho que la superficie radicular a cubrir; de esta manera aseguramos una vascularización periférica adecuada. Idealmente, se introucen dos tercios del ITC en el interior del bolsillo.
En la técnica original no se sutura el colgajo, sino que solamente se aplica un apósito de cianoacrilato. Esta técnica asegura un trauma quirúrgico mínimo, sin incisiones verticales ni suturas y con una estética adecuada de los tejidos postquirúrgicamente. Su limitación está en la dificultad de obtener suficiente tejido en zonas de recesión más extensas; por ello, esta técnica está indicada para el tratamiento de recesiones localizadas ${ }^{13}$ (fig.16)

\section{ITC supraperióstico tuneli- zado}

En 1994, Allen modificó la técnica de Raetzke para tratar de corregir algunas de sus limitaciones y hacerla extensible a múltiples zonas con recesión. La técnica consiste en incisiones intrasulculares a bisel interno, mediante una cureta afilada $u$ otros instrumentos modificados por el autor. Se diseca un colgajo de espesor parcial que creará una bolsa supraperióstica; ésta se extiende en sentido apical más allá de la línea mucogingival, y en sentido lateral un mínimo entre 3 a $5 \mathrm{~mm}$ respecto a las recesiones extremas. No se deben despegar los vértices de las papilas. El autor señala que en casos de periodontos muy finos y friables con riesgo de necrosis, el colgajo disecado puede ser de espesor total.

EI ITC debe ser 1 o 2 mm más corto que la longitud del lecho receptor y de un grosor mínimo de 1,5 mm $\mathrm{mm}^{9,14^{*}}$. Mediante un punto en colchonero en el tejido donante, éste es introducido a través de las papilas y de los tejidos interproximales a manera de túnel. cuando el injerto alcanza el extremo opuesto se fija con un punto colchonero. Se realiza otro punto colchone- 

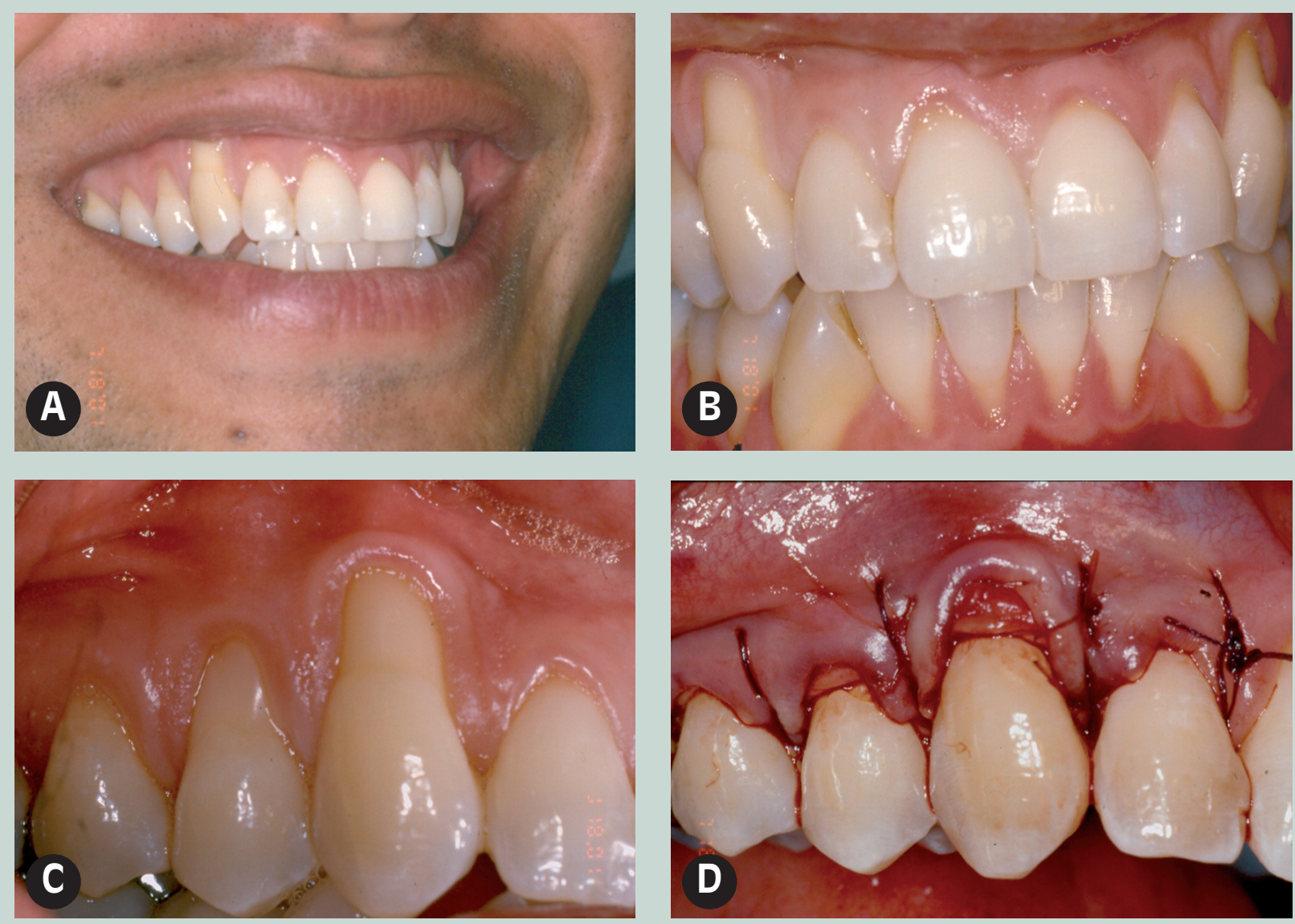

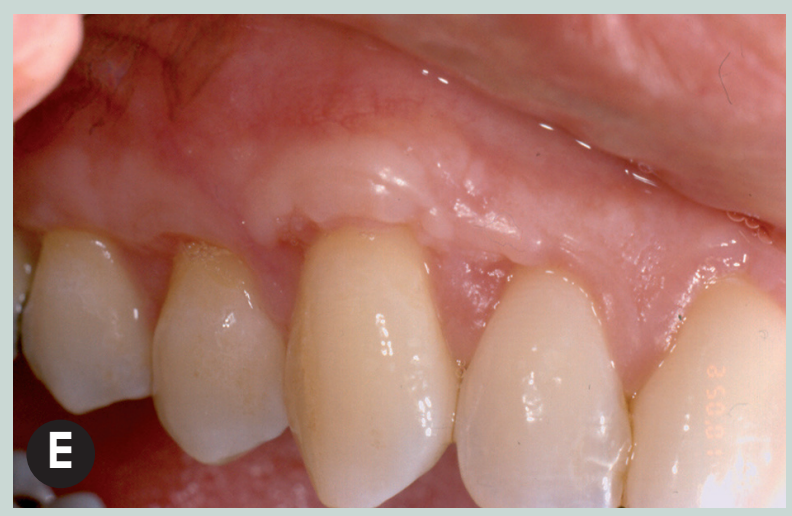

Figura 15.

Secuencia de ITC con colgajo parcial colocado en sentido coronal. (5 fotos). A. Linea de sonrisa. $\boldsymbol{B}$. Recesiones generalizadas. $C$. $R e-$ cesiones en \#13,14,15. D. ITC suturado. E. Resultado al mes.

ro en el extremo opuesto y los espacios interproximales se suturan con puntos simples.

El autor señala como indicaciones de esta técnica: zonas con mínima profundidad de sondaje, recesiones clase I y II de Miller, insuficiente cantidad o calidad de tejido para realizar un colgajo desplazado lateralmente, zonas de recesión localizadas o múltiples, grietas gingivales o márgenes gingivales irregulares que compro- metan la estética o dificulten la higiene oral, y casos de hipersensibilidad.

Como contraindicaciones se describen el tabaco y los factores que comprometan la vascularización y cicatrización de los tejidos, las bolsas periodontales o defectos óseos que requieran elevar un colgajo para su acceso, y las recesiones clase III o IV de Miller. En casos de inserciones aberrantes del frenillo, esta técnica no nos permite disecarlo, ya que las incisiones comprometerían el aporte vascular del injerto. La frenectomía debe realizarse de 4 a 6 semanas antes que el injerto ${ }^{14^{*}}$. 


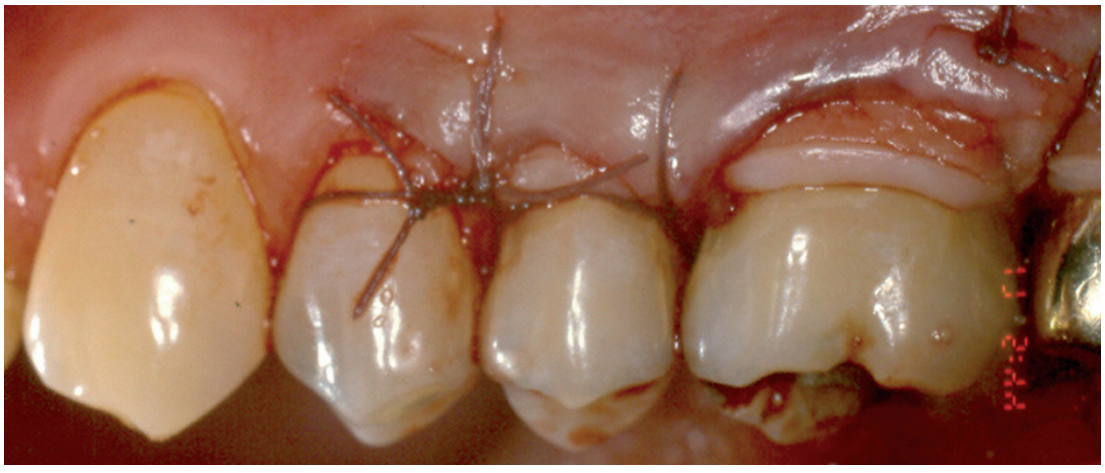

Figura 16. ITC en sobre supraperióstico sin descargas.

Las ventajas de este procedimiento serían el mínimo traumatismo del lecho, el aumento de la nutrición que proviene de las papilas y de las zonas laterales, la integridad de las papilas y la consecuente mejora de la estética final. El diseño del túnel permite suturar fácilmente asegurando una correcta fijación del injerto al lecho (fig.17).

\section{ITC asociado a colgajo de espesor parcial desplaza- do en sentido lateral}

Recomendado sólo en casos donde exista suficiente tejido queratinizado adyacente a la recesión. En 1956 Grupe y Warren ${ }^{18}$ describieron el colgajo de espesor total con desplazamiento lateral; posteriormente, se han propuesto modificaciones de esta técnica. En 1964, Staffilleno ${ }^{19}$ recomendó que el colgajo fuera de espesor parcial. Más recientemente, Zucchelliro y cols en 2004 han diseñado un colgajo desplazado lateral y coronalmente. Se realizan seis incisiones: dos horizontales, una en la zona donante y otra en la zona del colgajo desplazado, tres verticales y una oblicua. Se diseca un colgajo de espesor parcial. El ITC se coloca sobre la superficie radicular a tratar $y$ se fija mediante sutura reabsorbible $y$ puntos interrumpidos en las papilas. El colgajo es desplazado lateralmente cubriendo el tejido dador, se fija la parte más coronal mediante sutura suspensoria y se aplican puntos simples en las zonas laterales.

\section{ITC asociado a colgajo de doble papila}

En ciertos casos, la encía y la papila adyacente a la recesión son adecuadas, permitiendo desplazar las papilas de ambos lados para cubrir el defecto. Cohen y Ross ${ }^{21}$ encontraron ventajas de este colgajo frente al desplazado lateralmente.

Estará indicado en zonas sin pérdida de soporte interproximal.

Harris $^{22^{*}}$ empleó un injerto de tejido conectivo sobre la zona de la recesión y lo cubrió con un colgajo de doble papila. Obtuvo un cubrimiento completo en un $80 \%$ de los casos y una media de cubrimiento de la recesión del 97,4\%.

Se coloca un ITC sobre un lecho óseo o perióstico, y se cubre con un colgajo bipediculado. Se practican dos incisiones horizontales a cada lado de la recesión a tratar, en la base de ambas papilas y un milímetro por encima de la línea amelocementaria, abarcando la máxima cantidad de tejido interproximal pero sin dañar el margen gingival de los dientes adyacentes. En el margen gingival de la recesión se traza una incisión a bisel interno para eliminar el epitelio interno del surco. Partiendo de las incisiones horizontales se realizarán dos incisiones liberadoras ligeramente divergentes que se extienden más allá de la línea mucogingival y desde su extremo apical dos incisiones oblicuas hacia el centro del colgajo. La disección del colgajo puede ser a espesor total o parcial. Se coloca y fija el tejido conectivo mediante puntos colchoneros de manera que su borde coronal se encuentre a nivel de la línea amelocementaria. Los dos pedículos del colgajo se suturan mediante puntos simples y sutura reabsorbible. El colgajo se recoloca coronalmente cubriendo completamente el injerto.

\section{Injerto dérnico acelular. Alloderm ${ }^{\circledR}$}

Los injertos de tejido blando, en especial los de tejido conectivo, permiten excelentes resultados estéticos y de predictibilidad, pero su principal inconveniente es la limitación en la cantidad de tejido donante, especialmente en los casos en que es necesario el cubrimiento de múltiples recesiones.

Con el uso del injerto dérmico acelular (Alloderm®) se eliminan la necesidad de una zona donante, limitaciones en la cantidad de tejido, posibles complicaciones de una segunda herida quirúrgica y la morbilidad post operatoria que supone al paciente. 


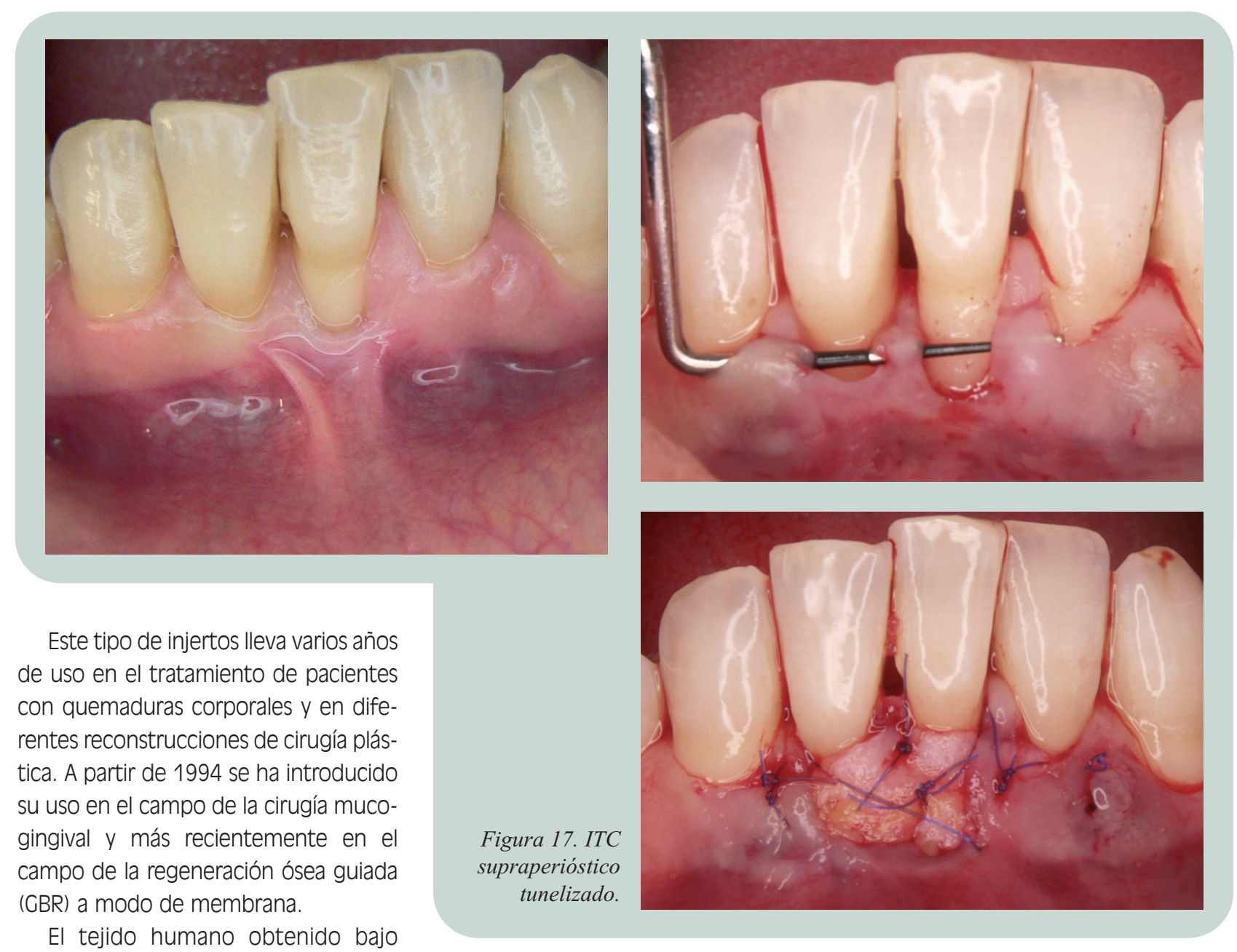

estricto control y seguimiento de los donantes es químicamente tratado con una solución buffer salina hasta eliminar la epidermis y el componente celular de la dermis, preservando sólo el tejido conectivo que actuará como matriz dérmica bioactiva, que será completamente revascularizada y repoblada por las células del receptor.

Al eliminar los componentes celulares (antígenos) se elimina toda fuente de transmisión y reacción inmunológica. Además los diferentes procesos de control a los que es sometido el material han demostra- do que en 10 años de uso y más de 500.000 injertos no se han reportado casos de transmisión viral.

El uso de estos injertos ha sido recomendado en diversas técnicas entre las que encontramos: aumento del grosor de la encía queratinizada alrededor de dientes e implantes, cubrimiento radicular en recesiones individuales o múltiples, preservación y/o aumento del grosor gingival en áreas desdentadas o eliminación de pigmentaciones melanóticas o tatuajes por metales.

A continuación señalamos su uso en el cubrimiento radicular ya que las técnicas son diversas, y no son objetivo de este artículo.

Las técnicas de cubrimiento radicular en el caso del injerto dérmico acelular son semejantes a las ya comentadas anteriormente. Resumiremos los pasos de la siguiente manera:

El primer paso consiste en la rehidratación del injerto con dos baños consecutivos cada uno durante 10 minutos en solución salina estéril.

Se preparará el área receptora reflejando un colgajo de espesor parcial o total. 

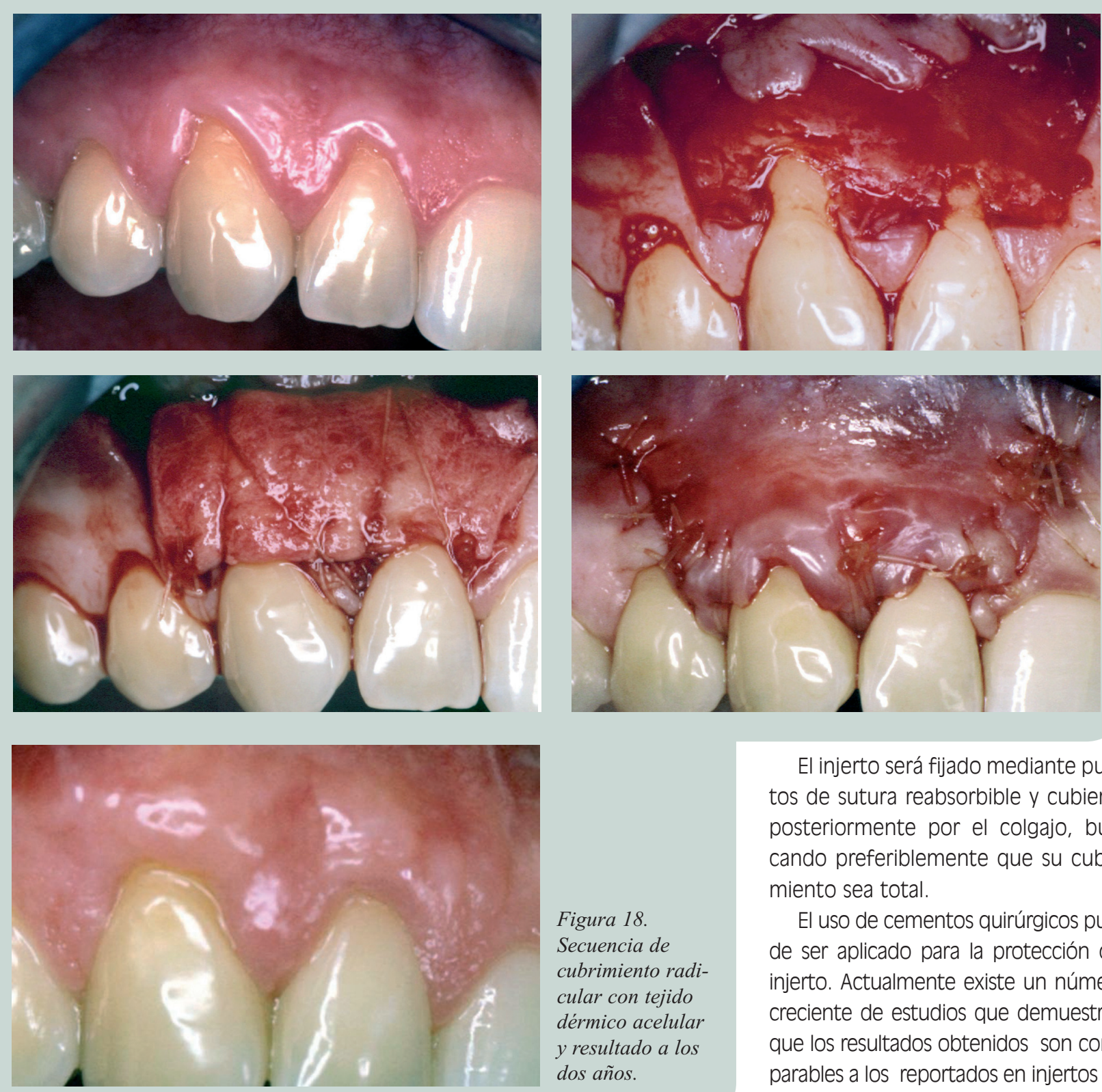

Figura 18.

Secuencia de cubrimiento radicular con tejido dérmico acelular y resultado a los dos años.

En el caso de este último, debemos asegurarnos de realizar pequeñas decorticaciones en la superficie ósea que nos garanticen la revascularización del injerto. Este colgajo puede hacerse mediante incisiones liberadoras 0 en sobre. Posteriormente, posi- cionamos el injerto en el área receptora. Se recomienda colocar la superficie que corresponde a la membrana basal hacia el colgajo y la cara del tejido conectivo hacia el lecho receptor; sin embargo, la literatura no muestra diferencias en este punto.
El injerto será fijado mediante puntos de sutura reabsorbible y cubierto posteriormente por el colgajo, buscando preferiblemente que su cubrimiento sea total.

El uso de cementos quirúrgicos puede ser aplicado para la protección del injerto. Actualmente existe un número creciente de estudios que demuestran que los resultados obtenidos son comparables a los reportados en injertos de tejido blando ${ }^{22 * 23}$ (fig. 18).

\section{Conclusiones}

Podemos señalar que las diversas técnicas de cubrimiento de las recesiones radiculares son tratamientos predecibles y con resultados estéticos 
aceptables. Sin embargo creemos importante realizar un buen diagnóstico preoperatorio de las característi- técnica más adecuada a cada caso y asegurar el éxito del tratamiento y el confort de los pacientes.

\section{Bibliografia recomendada}

Para profundizar en la lectura de este tema, el/los autor/es considera/an interesantes los artículos que aparecen señalados del siguiente modo: *de interés ${ }^{*}$ de especial interés.

1. Guinard EA, Caffesse RG. Localized gingival recessions: I Etiology and prevalence. J Western S Periodontol. 1977;25:3-9.

2**. Miller PD. A classification of marginal tissue recession. Int J Periodont Rest Dent.1985;2:913

Artículo clásico y de lectura obligada donde se describe la clasificación de las recesiones del tejido blando marginal más frecuentemente utilizada en periodoncia. Ha sido utilizada como clasificación de referencia para la predictibilidad del éxito del cubrimiento radicular.

3*. Gray J. When Not to Perform Root Coverage Procedures. J Periodontol. 2000;71:1048-9. Artículo de lectura necesaria por las exhaustivas recomendaciones sobre los factores a considerar al estudiar un caso candidato a cubrimiento radicular. Expone las indicaciones y posibles contraindicaciones de esta técnica quirúrgica.

4. Guimaraes A, Carleto D, Wilson A, Sallum E, Casati M, Nociti F. Smoking may affect root coverage outcome: a prospective clinical study in humans. J Periodontol. 2004;75:586-91.

5. Miller PD. Root coverage using free soft tissue autografts following acid application. I. Tecnique. Int J Periodont Rest Dent.1982;2:65-70.

6*. Sullivan H, Atkins J. Free Autogenous Gingival Grafts. I. Principles of Successful Grafting. Periodontics. 1968;6:121-9.

Artículo clásico de lectura obligatoria por ser la primera descripción de la técnica del injerto gingival libre. Detalla la preparación del lecho receptor, preparación de la zona dadora, inmovilización del injerto, cuidados postoperatorios y posibles complicaciones y limitaciones.

7. Oliver R., Löe H, Karring T. Microscopic evaluation of the healing and revascularization of the gingival grafts. J Clin Periodont Res. 1968;3:84-95.

8. Bernimoulin JP, Lüscher B, Mühleman HR. Coronally repositioned periodontal flap. Clinical evaluation after one year. J Clin Periodontol. 1975;2:1-13.
9. Hoolbrook T, Oschenbein C. Complete coverage of the denuded root surface with a onestatge gingival graft. Int $\mathrm{J}$ Periodont Rest Dent. 1983;3:9-27.

10. Caffesse R, De la Rosa M, Garza M, MunneTravers A, Mondragon J, Weltman R. Citric Acid Demineralization and Subepithelial Connective Tissue Grafts. J Periodontol. 2000;71:568-72.

11*. Haeri A, Serio F. Mucogingival surgical procedures: A review of the literature. Quintessence Int. 1999;30:475-83

Artículo de lectura necesaria por la exhaustiva revisión llevada a cabo sobre las diferentes técnicas de cirugía mucogingival. Describe los objetivos, indicaciones y factores para el éxito de estas técnicas quirúrgicas. Ayuda al clínico a seleccionar un procedimiento adecuado para cada paciente y obtener unos resultados más predecibles.

$12 * *$. Langer B, Langer L. Subepithelial connective tissue graft technique for root coverage. J Periodontol. 1985; 56:715-20. Artículo de gran interés donde el autor describe paso a paso la técnica del injerto de tejido connectivo subepitelial. Se exponen las ventajas de este procedimiento para el cubrimiento radicular de recesiones únicas o múltiples.

13. Raetzke PB. Covering localizated areas of root exposure employing the envelope technique. J Periodontol. 1985;56:397-402.

14*. Allen A. Use of the Supraperiosteal Envelope in Soft Tissue Grafting for Root Coverage. I. Rationale and Technique. Int J Periodontol Rest Dent. 1994; 14:217-27.

El autor describe una técnica quirúrgica para el cubrimiento radicular de múltiples recesiones mediante la preparación de un lecho receptor en túnel. Mediante ilustraciones detalla los pasos de la técnica quirúrgica y analiza las indicaciones y contraindicaciones de este procedimiento quirúrgico.

15. Harris RJ. A Comparision of two Techniques for Obtaining a Conective Tissue Graft
From the Palate. Int J Periodontol Rest Dent. 1997; 17:260-71.

16. Nelson S. The Subpedicle Connective Tissue Graft A Bilaminar Reconstructive Procedure for the Coverage of Denuded Root Surfaces. J Periodontal. 1987;58:95102.

17. Harris RJ. The connective tissue with partial thickness double pedicle graft. The results of 100 consecutively treated defects. J Periodontol. 1994;65:448-56.

18. Grupe HE, Warren RF. Repair of gingival defects by sliding flap operation. J Periodontol. 1956;27:92-5.

19. Staffileno H. Management of gingival recession and root exposure problems with periodontal disease. Dent Clin North Am. 1964; 3:111-20.

20. Zucchelli G, Cesari C, Amore C, Montebugnoli De Sanctis M. Laterally Moved, Coronally Advanced Flap : A modified Surgical Approach for Isolated Recession-Type Defects. J Periodontol. 2004;75:1734-41.

21. Cohen DW, Ross SE. The double papilla repositioned flap in periodontal therapy. $\mathrm{J}$ Periodontol. 1968;39:65-70.

$22 *$. Harris, RJ. A comparative study of root coverage obtained with an acellular dermal matrix versus a connective tissue graft: results of $\mathbf{1 0 7}$ recession defects in $\mathbf{5 0}$ consecutively treated patients. Int $\mathrm{J}$ Periodontics Restorative Dent. 2000;20:51-9.

El autor compara dos técnicas de cirugía mucogingival para el cubrimiento radicular. Se presentan los resultados de ambos procedimientos en relación al cubrimiento radicular obtenido y la cantidad de encía queratinizada ganada. No se obtuvieron resultados clínicos significativos entre ambas técnicas para la obtención de cubrimiento radicular.

23. Santos, A. Goumenos G, Pascual A. Management of Gingival Recession by the Use of an Acellular Dermal Graft Material: A 12-Case Series. J Periodontol. 2005;76:1982-90. 